Research Article, Issue 1
Analytical Methods in Environmental Chemistry Journal
AMECJ

\title{
Room temperature imidazolium-based ionic liquids as scavengers for hydrogen sulfide removal of crude oil
}

\author{
Ali Akbar Miran Beigia, ${ }^{a,}$, Maryam Yousefi ${ }^{a, b}$, and Majid Abdouss ${ }^{b}$ \\ ${ }^{a}$ Research Institute of Petroleum Industry, West Blvd. of Azadi Sport Complex, Tehran, Iran \\ ${ }^{\mathrm{b}}$ Department of Chemistry, Amirkabir University of Technology, P.O. Box 15875-4413, Tehran, Iran
}

ART I C L E I N F O:

Received 20 Aug 2018

Revised form 24 Oct 2018

Accepted 30 Nov 2018

Available online 25 Dec 2018

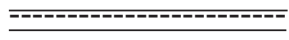

Keywords:

H2S removal

Crude oil

Ionic liquids

Commercial scavengers

Petroleum refining

\begin{abstract}
A B S T R A C T
Determination of $\mathrm{H}_{2} \mathrm{~S}$ amounts in crude oil was performed by a precise method instead of UOP163 that were developed in our pervious works. Evaluation of ILs and scavengers were done by two ways. The first one was based on variable concentration of ILs as the scavenger (dynamic method), and the second one was based on a constant concentration of the scavenger during $\mathrm{H}_{2} \mathrm{~S}$ removal process (static method). In the static method, design of experiments was performed for all three tested ILs and three parameters such as time, temperature, and dosage (injection volume) of ILs were investigated. A wide range of time and temperature was also studied according to operating conditions in petroleum terminals. The dose of ILs was obtained from the dynamic method. According to the obtained results, these ILs had a significant effect on $\mathrm{H}_{2} \mathrm{~S}$ reduction in crude oil, so that $\mathrm{H}_{2} \mathrm{~S}$ concentration in some conditions was less than $1 \mathrm{ppm}$. In comparison between ILs and commercial scavengers's performance can be properly understood that not only ILs reduced $\mathrm{H}_{2} \mathrm{~S}$ concentration, but also their dosage was very low, and mole ratio of $[\mathrm{IL}] /\left[\mathrm{H}_{2} \mathrm{~S}\right]$ was 1:3 that it was negligible compared with commercial scavengers. Also the results showed that [EMIM][NTf $\left.{ }_{2}\right]$ was more effective than the other ILs in $\mathrm{H}_{2} \mathrm{~S}$ removal.
\end{abstract}

\section{Introduction}

Hydrogen sulfide is one of the most abundant sulfur containing compounds in natural gas and light and middle distillate oil fractions as well as in atmospheric air effluents and pulp and paper industry. Hydrogen sulfide is undesirable, colorless, odorous, highly toxic, and poisonous for catalysts and corrosive to industrial gas and oil streams [1-3]. Also, it can be regarded as a major source of air pollution [4-6]. This acid gas is produced

\footnotetext{
${ }^{*}$ Corresponding author emails: miranbeigiaa@ripi.ir amiranbeigi@yahoo.com

DOI: https://doi.org/10.24200/amecj.v1.i01.32
}

along with methane and light hydrocarbons in many oil and gas fields [7, 8]. According $\mathrm{g}$ to the international environmental regulations, $\mathrm{H}_{2} \mathrm{~S}$ contained in the acid gases should be effectively removed before emission to atmosphere [8,9]. $\mathrm{H}_{2} \mathrm{~S}$ is commonly removed from natural and synthesis gases through chemical absorption using aqueous solutions of organic bases like single amines, amine mixtures, or mixtures of an amine and a salt of an amino acid [10-12]. Extensive research has been conducted by several groups on aqueous solutions of alkanolamines, especially 
monoethanolamine (MEA), diethanolamine (DEA) and methyldiethanolamine (MDEA) for treating and sweetening [13-16]. All of them are volatile and they show a reversible reaction that it can reverse $\mathrm{H}_{2} \mathrm{~S}$ in refining processes and make the process economically expensive [17].

In contrast ionic liquids (ILs) provides a vaporless, thermally stable $[18,19]$, reusable "green" solvent and catalyst for chemical reactions, so ILs has very possibility for removal of $\mathrm{H}_{2} \mathrm{~S}$. ILs are molten salts composed entirely of ions, and many of them are liquids at room temperature. Room temperature ionic liquids (RTILs), often referred to as 'designer solvents', have been the great focus of scientists in various fields since they can be tuned for specific applications [20-27]. Nowadays, the most commonly studied ILs normally contain, imidazolium, ammonium, phosphonium, pyridinium, and pyrrolidinium cations, and tetrafluoroborate, hexafluorophosphate, bistrifluorosulfonylimide and triflate anions [20, 25, 28-30]. In addition, the physicochemical properties of ILs can be finely tuned by slight structural changes of the corresponding cations and anions [23-26]. To better understand the nature of ionic liquids and rationally expand their applications especially as pollutant scavenger and electrolyte, knowledge of their thermophysical and electrochemical properties is required. In this work [Hmim][BF4], [Emim] $\left[\mathrm{Ntf}_{2}\right]$ and [Bmim] $\left[\mathrm{MeSO}_{4}\right]$ were used as scavengers for $\mathrm{H}_{2} \mathrm{~S}$ removal from crude oil and then the results were compared with several commercial scavengers. Molecular structures of the three ILs are shown in Fig. 1.

In our previous work, physical and electrochemical properties of these ILs were investigated. Viscosity, solubility, thermal decomposition and electrochemical window of three ILs were studied more than the other properties. So these mentioned properties have been applied for $\mathrm{H}_{2} \mathrm{~S}$ removal. For example, the viscosity of selected ILs was fully compatible with the crude oil. Therefore, use of them in crude oil was not a problem. The thermal stability of ILs was very high and their ability at high temperatures was excellent. ILs may be have hydrophilic or lipophilic properties.

The hydrophilic and lipophilic ILs can remove $\mathrm{H}_{2} \mathrm{~S}$ of aqueous and organic parts of crude oil respectively. The decomposition temperature ranges of three ILs are shown in Table 1. Also, the experimental values of physicochemical properties of $[\mathrm{HMIM}]\left[\mathrm{BF}_{4}\right],[\mathrm{EMIM}]\left[\mathrm{NTf}_{2}\right]$ and [BMIM] $\left[\mathrm{MeSO}_{4}\right]$, such as density, refractive index, dynamic and kinematic viscosities, $\mathrm{pH}$, and surface tension are listed in Table 2[20]. According to our previous studies these ILs are very suitable for $\mathrm{H}_{2} \mathrm{~S}$

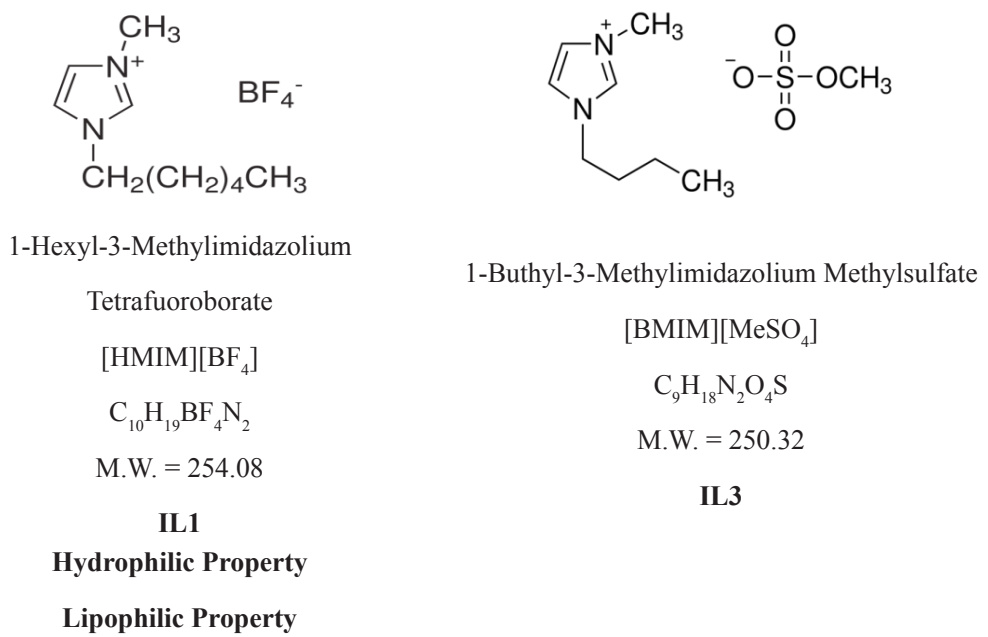

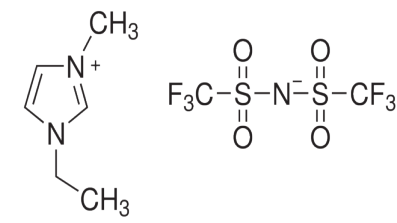

1-Ethyl-3-Methylimidazolium

bis(trifluoromethylsulfonyl)imide

[EMIM] $\left[\mathrm{NTf}_{2}\right]$

$\mathrm{C}_{8} \mathrm{H}_{11} \mathrm{~F}_{6} \mathrm{~N}_{3} \mathrm{O}_{4} \mathrm{~S}_{2}$

M.W. $=391.32$

IL2

Fig. 1. Molecular structures of the three ILs 
scavenging and to the best of our knowledge we didn't find any paper related to $\mathrm{H}_{2} \mathrm{~S}$ removal from crude oil by using ILs. In addition, these ILs unlike other scavengers don't have any disadvantages such as slow synthetics, high consumption, unstable in high temperatures, or increase salt and sediments content. Of course the elimination
Table 1. Thermal decomposition for investigated ionic liquids.

\begin{tabular}{ll}
\hline Ionic Liquid & $\begin{array}{l}\text { Decomposition } \\
\text { Temperature Range } /{ }^{\circ} \mathrm{C}\end{array}$ \\
\hline$[\mathrm{HMIM}]\left[\mathrm{BF}_{4}\right]$ & $310-500$ \\
{$[\mathrm{EMIM}]\left[\mathrm{NTf}_{2}\right]$} & $390-510$ \\
{$[\mathrm{BMIM}]\left[\mathrm{MeSO}_{4}\right]$} & $317-438$ \\
\hline
\end{tabular}

Table 2. Density $\rho$, dynamic viscosity $\eta$, refractive index $n_{D}$, surface tension $\sigma$, thermal expansion $a_{p}$, and $p H$ of the ionic liquids at different temperatures

\begin{tabular}{|c|c|c|c|c|c|c|}
\hline $\mathrm{t}\left({ }^{\circ} \mathrm{C}\right)$ & $\rho\left(\mathrm{g} \mathrm{mL}^{-1}\right)$ & $\eta(\mathrm{mPa} s)$ & $\mathrm{n}_{\mathrm{D}}$ & $\sigma\left(\mathrm{mN} \mathrm{m}^{-1}\right)$ & $10^{4} a_{p}(K)$ & $\mathrm{pH}$ of $1 \%$ Solution \\
\hline \multicolumn{7}{|c|}{$[\mathrm{HMIM}]\left[\mathrm{BF}_{4}\right]$} \\
\hline 10 & 1.1562 & 608.1 & 1.4265 & 41.4 & 5.343 & \\
\hline 20 & 1.1492 & 311.7 & 1.4241 & 40.6 & 5.525 & 6.41 \\
\hline 25 & 1.1461 & 220.0 & 1.4223 & 40.4 & 5.623 & 6.25 \\
\hline 30 & 1.1425 & 167.3 & 1.4211 & 40.0 & 5.718 & \\
\hline 40 & 1.1355 & 103.3 & 1.4183 & 39.8 & 5.909 & 5.77 \\
\hline 50 & 1.1280 & 63.77 & 1.4158 & 39.0 & 6.104 & \\
\hline 60 & 1.1214 & 52.22 & 1.4137 & 38.2 & 6.302 & 5.12 \\
\hline 70 & 1.1122 & 28.48 & 1.4106 & 37.2 & 6.504 & \\
\hline 80 & 1.1004 & 21.39 & 1.4080 & 36.6 & 6.709 & 4.49 \\
\hline 90 & 1.0874 & 15.87 & 1.4051 & 36.3 & 6.918 & 4.17 \\
\hline 95 & 1.0838 & 13.92 & 1.4038 & 35.9 & 7.025 & \\
\hline \multicolumn{7}{|c|}{$[\mathrm{EMIM}]\left[\mathrm{NTf}_{2}\right]$} \\
\hline 10 & 1.5311 & 55.92 & 1.4254 & 40.2 & 4.706 & \\
\hline 20 & 1.5220 & 37.27 & 1.4232 & 39.8 & 5.518 & 6.48 \\
\hline 25 & 1.5168 & 31.13 & 1.4220 & 39.4 & 5.929 & 6.5 \\
\hline 30 & 1.5117 & 26.28 & 1.4206 & 39.0 & 6.344 & \\
\hline 40 & 1.5020 & 19.67 & 1.4179 & 38.8 & 7.186 & 6.54 \\
\hline 50 & 1.4907 & 14.96 & 1.4153 & 38.6 & 8.045 & \\
\hline 60 & 1.4780 & 11.84 & 1.4127 & 38.0 & 8.925 & 6.60 \\
\hline 70 & 1.4651 & 9.506 & 1.4101 & 37.2 & 9.828 & \\
\hline 80 & 1.4494 & 7.820 & 1.4072 & 36.6 & 10.76 & 6.66 \\
\hline 90 & 1.4292 & 6.539 & 1.4045 & 36.0 & 11.72 & 6.69 \\
\hline 95 & 1.4230 & 6.054 & 1.4033 & 35.5 & 12.21 & \\
\hline \multicolumn{7}{|c|}{$[\mathrm{BMIM}]\left[\mathrm{MeSO}_{4}\right]$} \\
\hline 10 & 1.2117 & 220.6 & 1.4831 & 46.0 & 4.457 & \\
\hline 20 & 1.2053 & 122.3 & 1.4777 & 44.4 & 4.810 & 7.60 \\
\hline 25 & 1.2019 & 93.78 & 1.4771 & 43.7 & 4.988 & 7.55 \\
\hline 30 & 1.1983 & 73.35 & 1.4765 & 43.4 & 5.167 & \\
\hline 40 & 1.1923 & 46.85 & 1.4745 & 42.6 & 5.530 & 7.39 \\
\hline 50 & 1.1853 & 32.21 & 1.4719 & 42.0 & 5.899 & \\
\hline 60 & 1.1774 & 23.02 & 1.4694 & 41.2 & 6.274 & 7.18 \\
\hline 70 & 1.1668 & 17.05 & 1.4673 & 39.8 & 6.656 & \\
\hline 80 & 1.1538 & 13.14 & 1.4650 & 39.0 & 7.0453 & 6.96 \\
\hline 90 & 1.1400 & 10.34 & 1.4626 & 38.1 & 7.443 & 6.85 \\
\hline 95 & 1.1356 & 9.257 & 1.4615 & 37.6 & 7.645 & \\
\hline
\end{tabular}


reaction mechanism is unknown and our further studies certainly will be in this field.

In present work determination of $\mathrm{H}_{2} \mathrm{~S}$ amounts in crude oil was performed by the method that was presented by researchers at Research Institute of Petroleum Industry method (RIPI). [31] Then ILs was used in two different ways as scavengers for $\mathrm{H}_{2} \mathrm{~S}$ removal. Finally, the results of both methods were compared with several commercial scavengers. Also, in our next work, metallic nanoparticles will be synthesized in ionic liquids media for $\mathrm{H}_{2} \mathrm{~S}$ removal from crude oil.

\section{Experimental}

\subsection{Materials}

All chemicals and three ionic liquids were purchased from Merck, Aldrich and Fluka companies. The chemicals were used without further purification. Crude oil samples included exported crude oil such as Balarood, Masjed Soleyman, Soomar, Bahregan, and Furoozan.

\subsection{Experimental procedure}

The RIPI method was applied for determination of $\mathrm{H}_{2} \mathrm{~S}$ amounts in crude oil. As we have previously reported this method was based on preliminary extraction with voltammetric detection. This method offers several inherent advantages for $\mathrm{H}_{2} \mathrm{~S}$ determination. Voltammetric detection methods are specific, since other species are electrochemically inactive at potentials where $\mathrm{H}_{2} \mathrm{~S}$ is detected. Also, this technique is very sensitive. Apparatus for determination of hydrogen sulfide in crude oil is shown in figure 2. After the measurement of $\mathrm{H}_{2} \mathrm{~S}$ content in crude oil, evaluation of several commercial scavengers and the ILs was done. Unfortunately there was not a systematic and standardized method to evaluate the efficiency of scavengers. In present work two methods was applied for evaluation. One is related to RIPI, was based on constant concentration of ILs or commercial scavengers and the other one was based on variable concentration of them that is related to

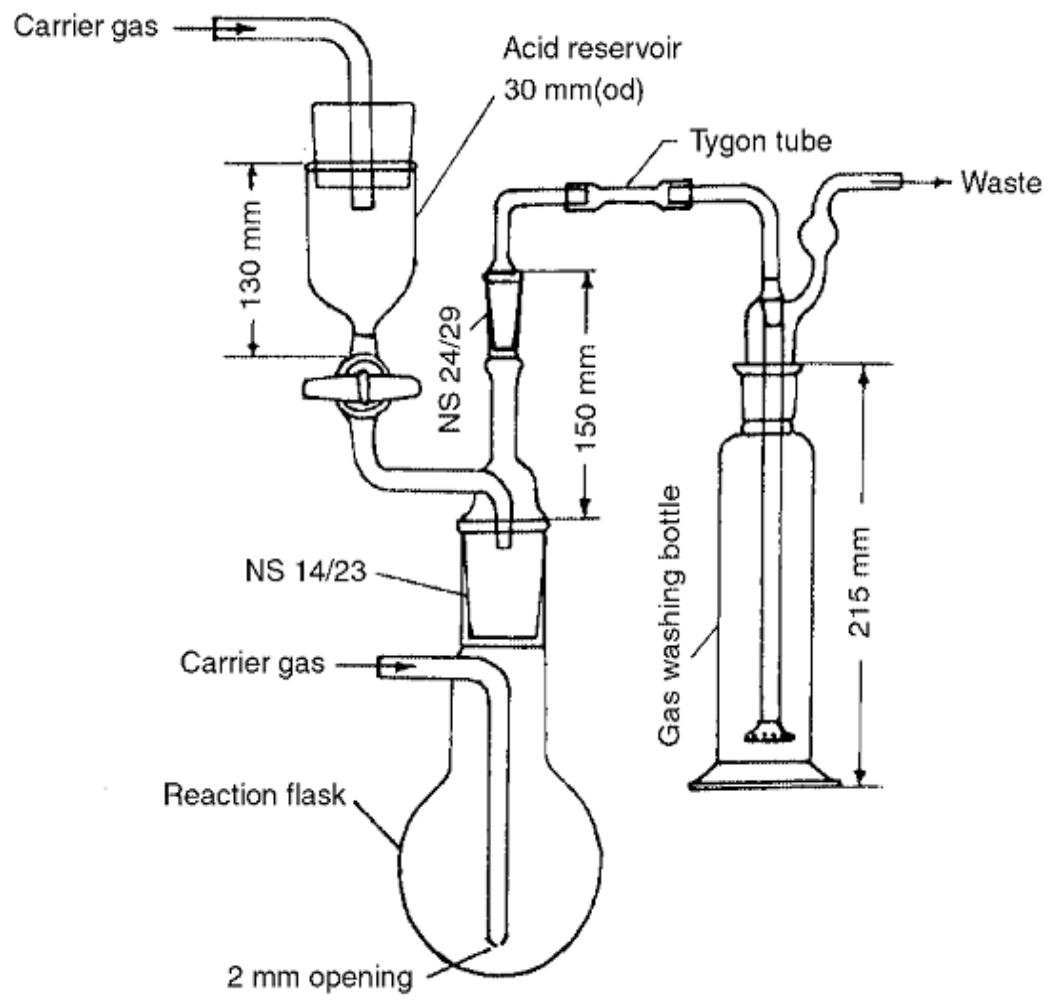

Fig. 2. The apparatus for determination of hydrogen sulfide in crude oil 
oil export terminals. In the constant concentration method for ILs, design of experiment was applied by using Design Expert software.

\section{Results and discussion}

\subsection{Evaluation of commercial scavengers}

Evaluation of commercial scavengers was developed by two methods.

\subsubsection{First method (Variable concentration)}

This method has been developed by the RIPI, had high operating speed. The scavengers that were used had fast kinetic and high efficiency. Evaluation in this method was based on measuring and following potential variations of crude oil during addition of scavengers in a specified time. A potential variation of crude oil was shown in figure 3 .

In the RIPI method, usually in the one minute intervals, approximately $50 \mu \mathrm{L}$ of scavenger was added to the certain amount of crude oil (about 100 g) and potential changes versus time and volume consumption of scavenger were recorded (Fig.3). Mutations that occurred in the potential curves were related to the equivalent point of $\mathrm{H}_{2} \mathrm{~S}$ titration by scavenger. In the equivalent point, almost all $\mathrm{H}_{2} \mathrm{~S}$ contents were neutralized by scavenger and crude oil are free of $\mathrm{H}_{2} \mathrm{~S}$.

Primary investigations showed that electrode potential was depended on $\mathrm{H}_{2} \mathrm{~S}$ or $\mathrm{S}$ concentration in crude oil. As long as hydrogen sulfide was present in the crude oil, electrode potential, depending on the $\mathrm{H}_{2} \mathrm{~S}$ concentration in the specified range was nearly between -900 up to $-1200 \mathrm{mV}$. It should be noted that beside $\mathrm{H}_{2} \mathrm{~S}$ concentration the electrode potential could be a function of temperature and electrolyte. Also, according to the Nernst equation, the electrode potential is depend on oxidative and reductive concentration, ions mobility and activity coefficient. Therefore, the potential ranges difference between -900 to $-1200 \mathrm{mV}$ may be due to one of the items listed above. In this method, evaluation of $\mathrm{H}_{2} \mathrm{~S}$ reduction was based on

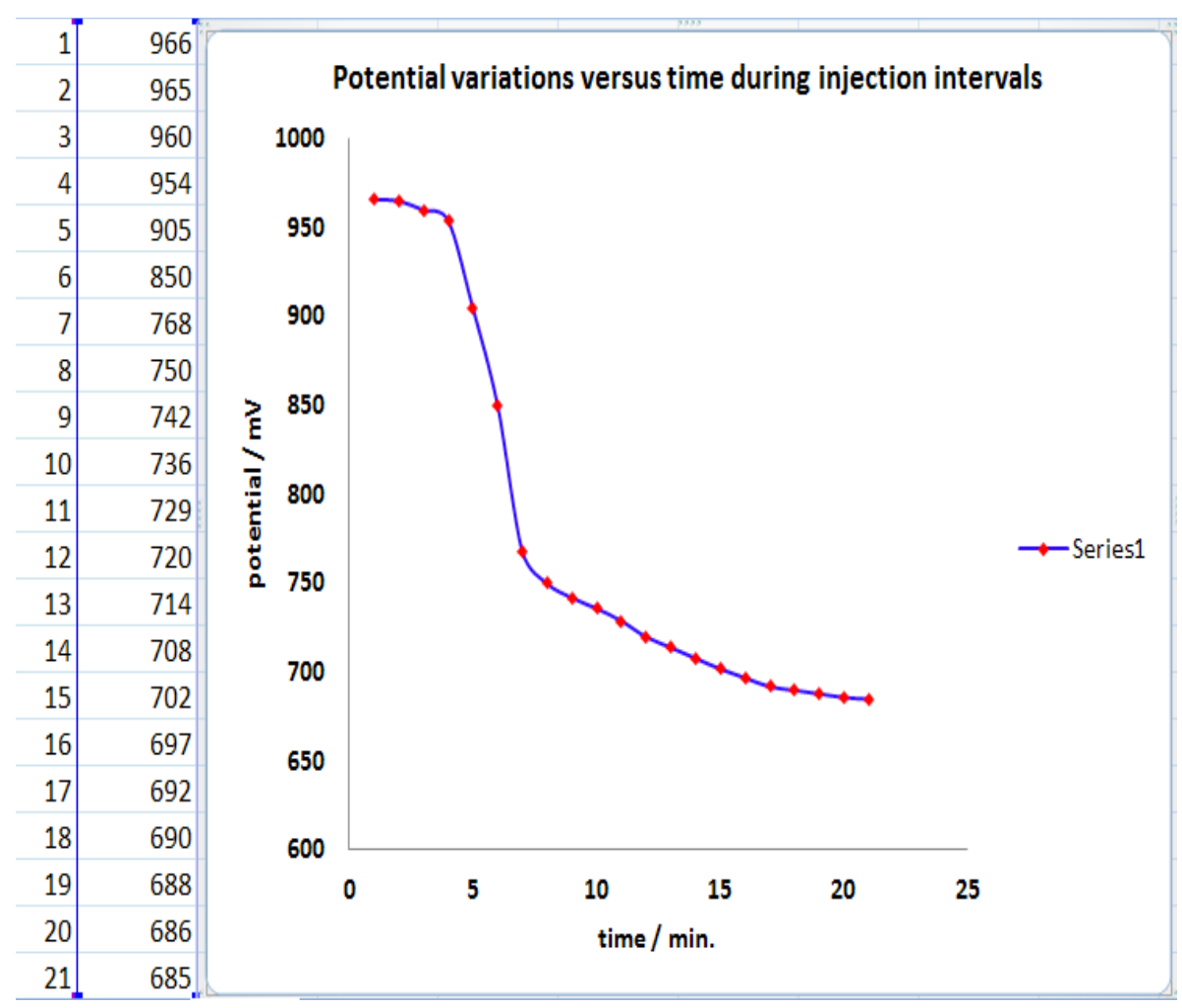

Fig. 3. Potential variations of crude oil by addition of a commercial scavenger versus time. 
Table 3. Evaluation of commercial scavengers using RIPI method

\begin{tabular}{ccccc}
\hline Sample name & Injection volume/ml & $\begin{array}{c}\mathrm{E} \\
\text { (initial)/mv }\end{array}$ & $\begin{array}{c}\mathrm{E} \\
\text { (final)/mv }\end{array}$ & Treatment time/min \\
\hline sulfavent 32 & 0.65 & 1100 & 805 & 15 \\
sulfavent 42 & 0.55 & 1080 & 810 & 10 \\
sulfavent 43 & 1 & 1000 & 860 & 7 \\
sulfavent 44 & 1 & 1100 & 945 & 12 \\
\hline
\end{tabular}

decreasing of the electrode potential. Experience indicated that when the crude oil was free of $\mathrm{H}_{2} \mathrm{~S}$, electrode potential shifted to nearly less than -750 up to $-800 \mathrm{mV}$. To more accurate investigations, 4 samples of commercial scavengers were tested using this method, and the results are given in Table 3.

As can be observed, sulfavent 32 and sulfavent 43 had better efficiency than the others. Lesser amounts of sulfavent 32 were used, on the other hand, Sulfavent 43 had higher speed. So that, for the neutralization of $\mathrm{H}_{2} \mathrm{~S}$ in crude oil, only $1 \mathrm{ml}$ of scavenger was needed during 7 minutes. Although, both methods gave same results in the selection of scavengers, but the RIPI method provided more information, such as the effective time of scavenger and equivalent point.

\subsubsection{Second method (Constant concentration)}

This method was based on instructions of oil export terminals. First, the amount of $\mathrm{H}_{2} \mathrm{~S}$ was measured in crude oil and then specific dosage of scavengers was added to the crude oil. The consumed volume of scavenger (was related to $\mathrm{H}_{2} \mathrm{~S}$ concentration.

Here, $\mathrm{H}_{2} \mathrm{~S}$ concentration was based on the amount of hydrogen sulfide in crude oil, which is usually between 50 to $100 \mathrm{ppm}$ of scavenger and depending on its efficiency, was about 2 to 5 times of the amount of $\mathrm{H}_{2} \mathrm{~S}$ in crude oil.

In a general evaluation, $100 \mathrm{~g}$ of a crude oil containing $75 \mathrm{ppm} \mathrm{H}_{2} \mathrm{~S}$, was chosen. Then $225 \mathrm{ppm}$ ([Scavenger $] /\left[\mathrm{H}_{2} \mathrm{~S}\right]: 3$ ) of the scavenger was added to it. After an hour stirring at room temperature, the $\mathrm{H}_{2} \mathrm{~S}$ concentration was measured with RIPI method. The same experimental conditions were done for an overnight and the results were reported and compared. Accordingly, all four samples were tested and the results are shown in Table 4.

Since the experiments were conducted on consecutive days, and there was no possibility of $\mathrm{H}_{2} \mathrm{~S}$ amount stabilization. So, the results were normalized in first and the last columns. As can be seen in the table, without any commercial scavenger, $\mathrm{H}_{2} \mathrm{~S}$ concentration has reached to $43 \mathrm{ppm}$ after an overnight, but by mistake this reduction was generally considered to be scavenger. As a result, long reaction time was one of disadvantages in this method.

The result showed that all scavengers, with the exception of Sulfavent 44, had the ability to remove

Table 4. Evaluation of commercial scavengers using constant concentration of scavenger

\begin{tabular}{lcccc}
\hline sample name & $\begin{array}{c}\text { H2S content in crude } \\
\text { befor treatment / ppm }\end{array}$ & $\begin{array}{c}\mathrm{H} \text { 2S content in crude } \\
\text { after 1 hour treatment / } \\
\mathrm{ppm}\end{array}$ & $\begin{array}{c}\mathrm{H} \text { 2S content in } \\
\text { crude after overnight } \\
\text { treatment / ppm }\end{array}$ & $\begin{array}{c}\text { H2S content in crude } \\
\text { before treatment after } \\
\text { overnight / ppm }\end{array}$ \\
\hline sulfavent 32 & 75 & 10.5 & $<1.0$ & 43 \\
sulfavent 42 & 75 & 47.0 & $<1.0$ & 43 \\
sulfavent 43 & 75 & 5.4 & $<1.0$ & 43 \\
sulfavent 44 & 75 & 26.0 & $<17$ & 43 \\
\hline
\end{tabular}


$\mathrm{H}_{2} \mathrm{~S}$ from crude oil. Whereas both Sulfavent 32 and 43 had satisfactory results after an hour. It seems that this method, where to store crude oil before loading, is appropriate. In the second method, which was developed by RIPI, those of scavengers that had rapid reaction kinetics (less than $15 \mathrm{~min}$ ) will be successful in reduction or elimination of $\mathrm{H}_{2} \mathrm{~S}$ from crude oil.

\subsection{Evaluation of Ionic Liquids}

\subsubsection{First method (Variable concentration)}

The basis of this method, as was explained in the case of scavengers, was based on gradual addition of ionic liquids and measuring and following potential variations of crude oil. First, the amount of $\mathrm{H}_{2} \mathrm{~S}$ was measured in crude oil, then $20 \mathrm{ml}$ of isopropyl alcohol and $30 \mathrm{ml}$ of toluene was added to $50 \mathrm{~g}$ of crude oil that containing $100 \mathrm{ppm}$ of $\mathrm{H}_{2} \mathrm{~S}$. At the beginning, electrode potential was read, then certain amount of ionic liquid (approximately 10 $\mu 1$ ) was added to crude oil in the same time intervals and potential variations was recorded. Fig. 4 shows the potential variations versus time for three ionic liquids. Also, in this method, the required volume of ionic liquid to minimize concentration to less than $15 \mathrm{ppm}$ of $\mathrm{H}_{2} \mathrm{~S}$ was determined. When the electrode potential shifted to less than $-800 \mathrm{mV}$, $\mathrm{H}_{2} \mathrm{~S}$ concentration was less than $15 \mathrm{ppm}$.

As can be seen in this chart, the ILs have been able to reduce $\mathrm{H}_{2} \mathrm{~S}$ concentration to less than 1 ppm, in a short time (less than 30 minutes). Also, the mole ratio of $[\mathrm{IL}] /\left[\mathrm{H}_{2} \mathrm{~S}\right]$ was $2.3,1.3$, and 2.5 for $[\mathrm{HMIM}]\left[\mathrm{BF}_{4}\right]$, [EMIM] $\left[\mathrm{NTf}_{2}\right]$, and [BMIM] $\left[\mathrm{MeSO}_{4}\right]$ respectively that these were equal to 75 $\mu 1,48 \mu 1$ and $76 \mu 1$ of ionic liquids. These values were negligible in comparison to commercial scavengers. Also among the three ionic liquids, [EMIM] $\left[\mathrm{NTf}_{2}\right]$ had a higher efficiency in $\mathrm{H}_{2} \mathrm{~S}$ removal from crude oil. Since [EMIM] $\left[\mathrm{NTf}_{2}\right]$ is lipophilic and its viscosity is closer to crude oil's viscosity, it can be better $\mathrm{H}_{2} \mathrm{~S}$ scavenger, moreover the consumed volume of $\mathrm{IL}_{2}$ is less than the others.

\subsubsection{Second method (Constant concentration)}

In this method, the $\mathrm{H}_{2} \mathrm{~S}$ concentration was measured in $15 \mathrm{~g}$ of crude oil, then specific dosage or concentration of ionic liquid was added to the crude oil. In fact, according to the dynamic

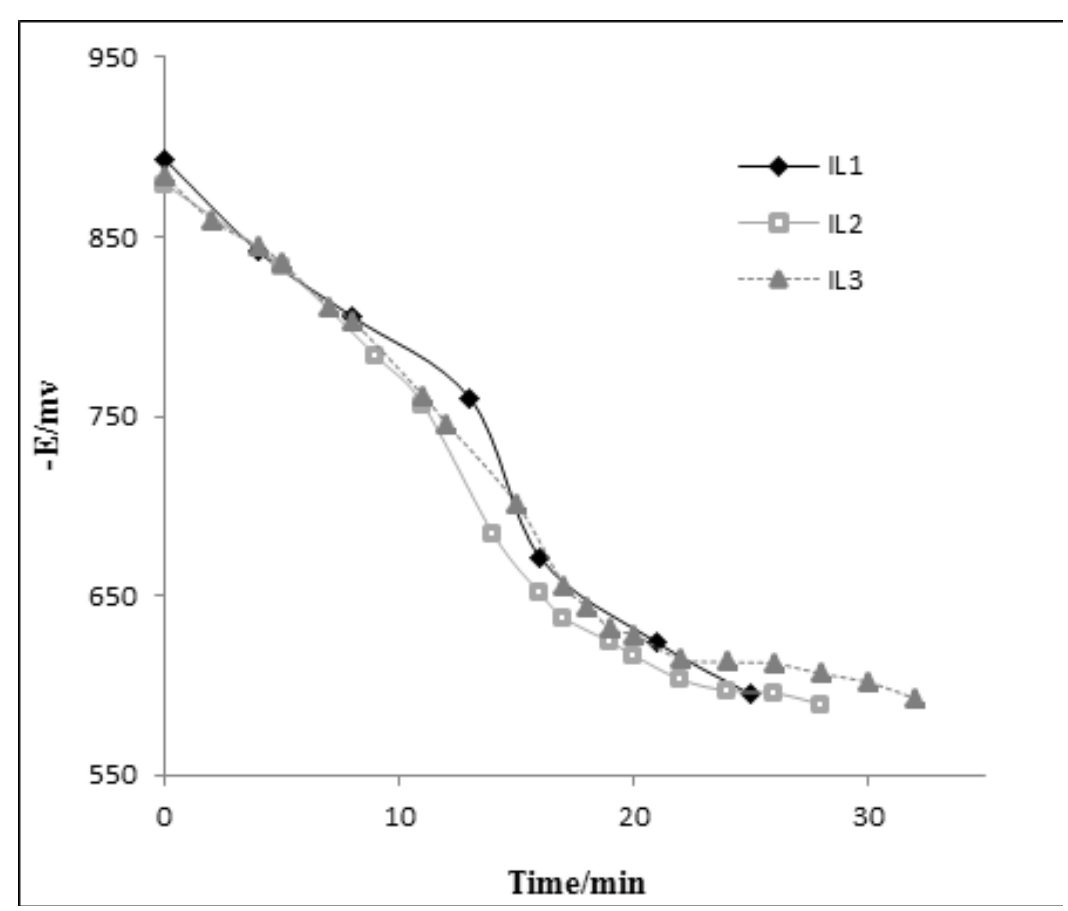

Fig. 4. The electrode response versus time during the gradual addition of the ionic liquid in crude oil. 
method results and operating condition in crude oil terminals, the required time, temperature and dosage of ILs, were determined for $\mathrm{H}_{2} \mathrm{~S}$ removal. Finally, after considering the conditions in crude oil terminals (crude oil temperature, scavenger dosage and duration the crude oil passes through pipeline) and according to dynamic method results, it can be concluded that the required amount of ILs to remove $\mathrm{H}_{2} \mathrm{~S}$ should be selected from 1 to 3 [IL]/ $\left[\mathrm{H}_{2} \mathrm{~S}\right]$ mole ratio, the reaction time from $25 \mathrm{~min}$ to $35 \mathrm{~min}$ and the temperature from $20^{\circ} \mathrm{C}$ to $50^{\circ} \mathrm{C}$, should be selected. After identifying these factors design of experiment was performed for each IL, using Design Expert software.

\subsubsection{Design of experiment}

As mentioned, the effective parameters or factors on $\mathrm{H}_{2} \mathrm{~S}$ concentration was detected by using dynamic method. Then design of experiment was performed using Expert design software that contained 20 runs or tests for each IL and various conditions such as dosage, temperature and reaction time, was applied separately for each run. The results are given in Table. 5. As can be seen in this table, first the concentration of $\mathrm{H}_{2} \mathrm{~S}$ was 100 ppm and after applying various conditions, such as dosage, time and temperature, $\mathrm{H}_{2} \mathrm{~S}$ concentration was reduced even less than $1 \mathrm{ppm}$. Columns 5 to 8 were normalized, because in some cases, $\mathrm{H}_{2} \mathrm{~S}$ concentration was more than $100 \mathrm{ppm}$, therefore all results were normalized to $100 \mathrm{ppm}$. It is obvious that if IL dosage, time and temperature was grater, $\mathrm{H}_{2} \mathrm{~S}$ concentration was lower.

Runs 4 and 14 for IL2 and crude oil sample without using ionic liquids are briefly reviewed in Table 6. $\mathrm{H}_{2} \mathrm{~S}$ concentration at the beginning was 113.27 ppm that was normalized to $100 \mathrm{ppm}$ after $35 \mathrm{~min}$ stirring at $30{ }^{\circ} \mathrm{C}$. The electrode potential shifted to $-675 \mathrm{mV}$ indicated that $\mathrm{H}_{2} \mathrm{~S}$ concentration was reached to less than $1 \mathrm{ppm}$. Also after run $14, \mathrm{H}_{2} \mathrm{~S}$

Table 5. Design of experiment for three ionic liquids

\begin{tabular}{cccccccc}
\hline $\begin{array}{c}\text { Run } \\
\text { Order }\end{array}$ & Temp/ ${ }^{\circ} \mathrm{C}$ & Time $/$ min & Dose $[\mathrm{IL}] /\left[\mathrm{H}_{2} \mathrm{~S}\right]$ & $\begin{array}{c}\mathrm{ppm} \mathrm{H}_{2} \mathrm{~S} \text { before } \\
\text { treatment }\end{array}$ & ppm $\mathrm{H}_{2} \mathrm{~S}$ IL1 & ppm $\mathrm{H}_{2} \mathrm{~S}$ IL2 & ppm $\mathrm{H}_{2} \mathrm{~S}$ IL3 \\
\hline 1 & 35 & 30 & 2 & 100 & 21.3 & 27.3 & 14.82 \\
2 & 20 & 25 & 1 & 100 & 78.5 & 32.5 & 62.95 \\
3 & 35 & 30 & 2 & 100 & 17.2 & 22.46 & 19.63 \\
4 & 50 & 35 & 1 & 100 & $<1.0$ & $<1$ & $<1$ \\
5 & 20 & 35 & 3 & 100 & $<1.0$ & 9.3 & 17.51 \\
6 & 50 & 25 & 3 & 100 & $<1.0$ & 4.02 & $<1$ \\
7 & 35 & 30 & 2 & 100 & 19.0 & 20.79 & 19.85 \\
8 & 35 & 30 & 4 & 100 & $<1.0$ & 7.3 & 3.1 \\
9 & 35 & 30 & 0.4 & 100 & 38.5 & 48.9 & 27.46 \\
10 & 11 & 30 & 2 & 100 & 32.3 & 41.83 & 26.27 \\
11 & 35 & 30 & 2 & 100 & 18.4 & 18.55 & 19.04 \\
12 & 60 & 30 & 2 & 100 & $<1.0$ & 3.93 & $<1$ \\
13 & 35 & 22 & 2 & 100 & 21.4 & 30.47 & 35.79 \\
14 & 35 & 38 & 2 & 100 & $<1.0$ & 8.2 & 4.34 \\
15 & 35 & 30 & 2 & 100 & 20.7 & 21.41 & 17.69 \\
16 & 35 & 30 & 2 & 100 & 19.2 & 19.10 & 15.60 \\
17 & 20 & 35 & 1 & 100 & 6.1 & 11.1 & 38.25 \\
18 & 50 & 35 & 3 & 100 & $<1.0$ & $<1$ & $<1$ \\
19 & 50 & 25 & 1 & 100 & 8.4 & 11.3 & $<1$ \\
20 & 20 & 25 & 3 & 100 & 23.3 & 14.32 & 24.55 \\
\hline
\end{tabular}


Table 5. Continue of Design of experiment for three ionic liquids.

\begin{tabular}{cccccccc}
\hline & weight & $\begin{array}{c}\text { Volume } \\
\text { consumption of } \\
\text { AgNO3 }\end{array}$ & $\begin{array}{c}\text { Initial } \\
\mathbf{p o t e n t i a l} \\
(\mathbf{m V})\end{array}$ & $\begin{array}{c}\mathbf{H}_{2} \mathbf{S} \\
(\mathbf{p p m})\end{array}$ & $\begin{array}{c}\text { Time } \\
(\mathbf{m i n})\end{array}$ & $\begin{array}{c}\text { Temperature } \\
\left({ }^{\circ} \mathbf{C}\right)\end{array}$ & Dose $[\mathbf{I L}] /\left[\mathbf{H}_{2} \mathbf{S}\right]$ \\
\hline Crude oil & 10.2 & 7.2 & -1100 & 113.3 & - & - & - \\
IL2 (Run 4) & 15.0 & - & -670 & $<1.0$ & 35 & 50 & $\mathbf{1}$ \\
IL2 (Run 5) & 15.0 & - & -575 & $<1.0$ & 35 & 20 & $\mathbf{3}$ \\
\hline
\end{tabular}
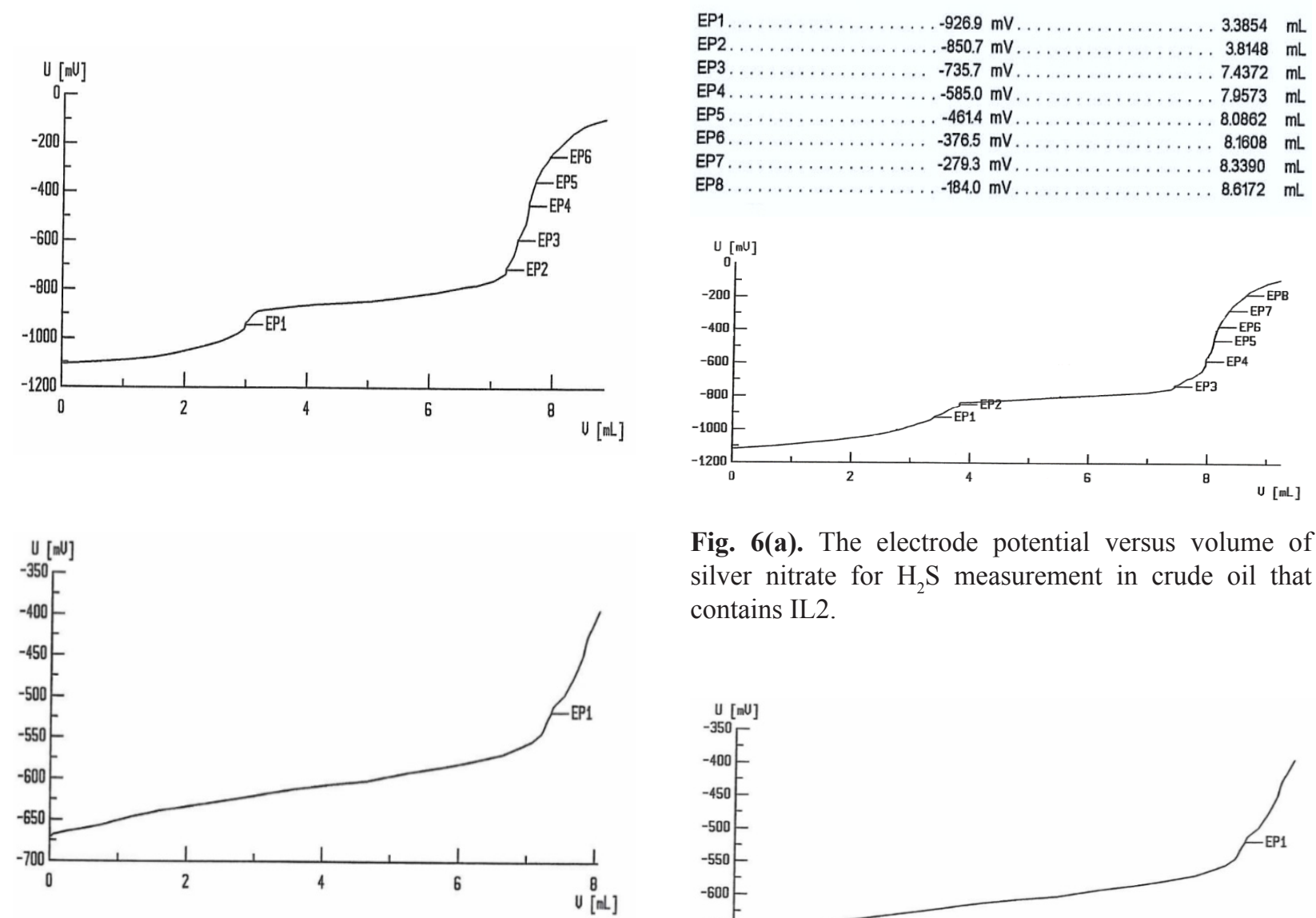

Fig. 6(a). The electrode potential versus volume of silver nitrate for $\mathrm{H}_{2} \mathrm{~S}$ measurement in crude oil that contains IL2.
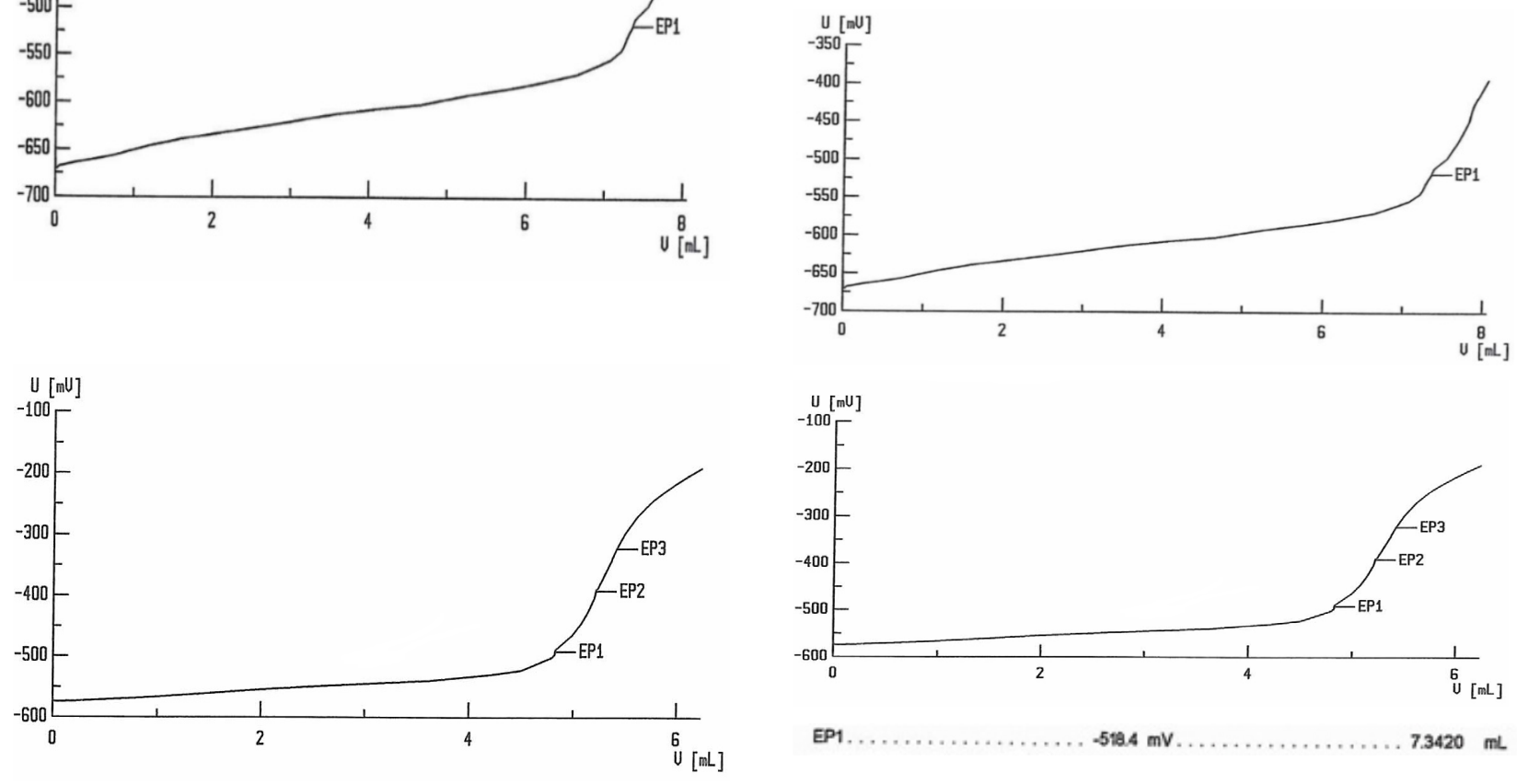

Fig. 5. The electrode potential versus volume of silver nitrate for $\mathrm{H}_{2} \mathrm{~S}$ measurement in crude oil.

Fig. 6(b). The electrode potential versus volume of silver nitrate for $\mathrm{H}_{2} \mathrm{~S}$ measurement in crude oil that contains IL2 
concentration was decreased from $113.27 \mathrm{ppm}$ to less than $1 \mathrm{ppm}$. The potentiometric curves for crude oil, runs 4 and 14 are presented respectively in figure 5.

The first chart showed $\mathrm{H}_{2} \mathrm{~S}$ concentration before addition of ionic liquids and the second one showed $\mathrm{H}_{2} \mathrm{~S}$ concentration after addition of ionic liquids in a special time and temperature. The electrode potential versus volume of silver nitrate was shown in Fig. 5 and $\mathrm{H}_{2} \mathrm{~S}$ concentration can be calculated before and after of ILs addition, according to the following formula.

$\mathrm{H}_{2} \mathrm{~S}$ concentration before Run 4 and Run 14 for [EMIM][ $\mathrm{NTf}_{2}$ ] was $116.66 \mathrm{ppm}$ as shown in figure 6a and $6 \mathrm{~b} . \mathrm{H}_{2} \mathrm{~S}$ concentration was diminished to less than 10 ppm after the Runs 4 and 14. figure 7 and 8 showed the electrode potential versus volume consumption of silver nitrate for runs 4 and 14 respectively. The EP3 (third equivalent point) for run 4 and EP1 for run 14 showed the required volume consumption of silver nitrate that neutralized $\mathrm{H}_{2} \mathrm{~S}$ amounts in crude oil.

Because the electrode potential was started with $-675 \mathrm{mV}$, as a result $\mathrm{H}_{2} \mathrm{~S}$ concentrations is less than $1 \mathrm{ppm}$.

We found that all three parameters had significant effect in $\mathrm{H}_{2} \mathrm{~S}$ removal by obtained results of this software. Here a few charts are examined briefly in figure 8 .

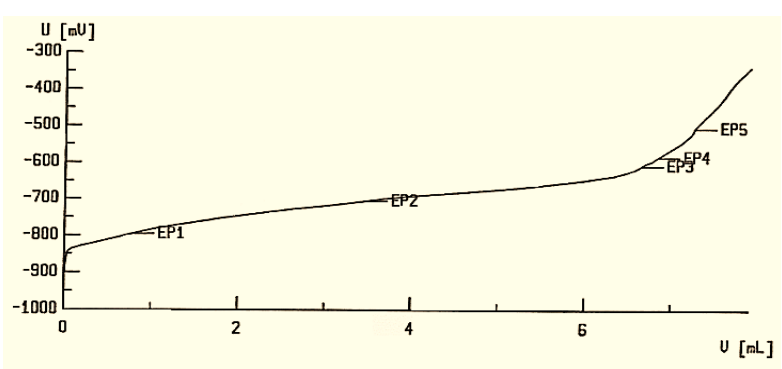

Fig. 7. The electrode potential versus volume of silver nitrate for $\mathrm{H}_{2} \mathrm{~S}$ measurement in crude oil that contains IL2.
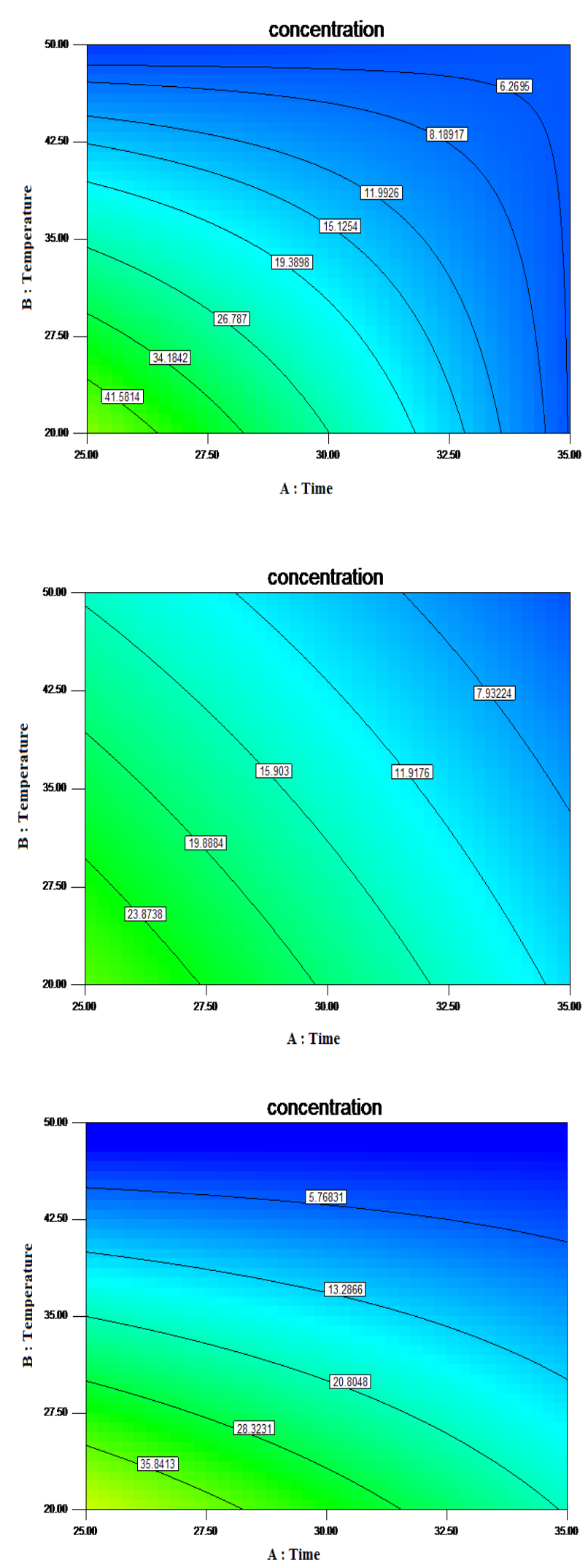

Fig. 8. Curves of temperature versus time at constant dosage. 
These figures showed that at constant dosage, if temperature and time were grater, $\mathrm{H}_{2} \mathrm{~S}$ concentration was less. Also [EMIM] $\left[\mathrm{NTf}_{2}\right]$ had better efficiency than the other ILs in $\mathrm{H}_{2} \mathrm{~S}$ removal, because it reduced $\mathrm{H}_{2} \mathrm{~S}$ concentration to less than $15 \mathrm{ppm}$ in a short time.

\section{Conclusions}

The results showed that all three ionic liquids were chosen correctly, because all of them are suitable for $\mathrm{H}_{2} \mathrm{~S}$ removal from crude oil. The investigation of chemical and physical properties of ionic liquids that all results were presented in our previous work, were indicated that some properties such as high thermal stability, $\mathrm{pH}$, solubility, and wide electrochemical windows, defined them as a suitable scavenger to $\mathrm{H}_{2} \mathrm{~S}$ removal. Using ionic liquids in the limited situation, and at low concentrations of $\mathrm{H}_{2} \mathrm{~S}$, is effective for crude oil sweetening. In comparison between commercial scavengers and ionic liquids and according to the obtained results from dynamic method and design of experiments, it is found by us that ILs is more effective than commercial scavengers because the volume consumption of ILs is less than the scavengers. Also, ILs could reduce $\mathrm{H}_{2} \mathrm{~S}$ concentration to less than $1 \mathrm{ppm}$. In design of experiments, three parameters (dosage, time and temperature) were investigated which all of them are effective in $\mathrm{H}_{2} \mathrm{~S}$ removal, and time is the most effective parameter. In addition, the results of dynamic method and design of experiment show that $[\mathrm{EMIM}]\left[\mathrm{NTf}_{2}\right]$ has better performance; in addition, the lower dosage of it has been spent.

\section{References}

[1] H. Sakhaeinia, V. Taghikhani, A. H. Jalili, A. Mehdizadeh, A. A. Safekordi, Solubility of $\mathrm{H}_{2} \mathrm{~S}$ in 1-(2-hydroxyethyl)-3-methylimidazolium ionic liquids with different anions, Fluid Phase Equilibria, 298 (2010) 303-309.

[2] R.C. Sahu, R. Patel, B.C. Ray, Removal of hydrogen sulfide using red mud at ambient conditions, Fuel
Pro. Tech., 92 (2011) 1587-1592.

[3] N.N. Nassar, M.M. Husein, P. Pereira-Almao, Ultradispersed particles in heavy oil: part II, sorption of $\mathrm{H}_{2} \mathrm{~S}$ (g), Fuel Pro. Tech. 91 (2010) 169174.

[4] N. Haimour, R. El-Bishtawi, A. Ali-Wahbi, Equilibrium adsorption of hydrogen sulfide onto $\mathrm{CuO}$ and $\mathrm{ZnO}$, Desalination, 181 (2005) 145-152.

[5] T.H. Ko, H. Chu, H.P. Lin, C.Y. Peng, Red soil as a regenerable sorbent for high temperature removal of hydrogen sulfide from coal gas, J. Hazard. Mater., B136 (2006) 776-783.

[6] J.B. Chung, J.S. Chung, Desulfurization of $\mathrm{H}_{2} \mathrm{~S}$ using cobalt-containing sorbents at low temperatures, Chem. Eng. Sci., 60 (2005) 1515-1523.

[7] A.H. Jalili, A. Mehdizadeh, M. Shokouhi, A. N. Ahmadi, M. Hosseini-Jenab, F. Fateminassab, Solubility and diffusion of $\mathrm{CO}_{2}$ and $\mathrm{H}_{2} \mathrm{~S}$ in the ionic liquid 1-ethyl-3-methylimidazolium ethyl sulfate, J. Chem. Thermodyn., 42 (2010) 1298-1303.

[8] Y. Duan, Y. Xiang, D. Xia, Removal of hydrogen sulfide from light oil with solid base, Fuel Pro. Technol., 86 (2004) 237-244.

[9] M.A. Sayyadnejad, H.R. Ghaffarian, M. Saeidi, Removal of hydrogen sulfide by zinc oxide nanoparticles in drilling fluid, Int. J. Environ. Sci. Tech., 5 (2008) 565-569.

[10] M.B. Shiflett, A. Yokozeki, Separation of $\mathrm{CO}_{2}$ and $\mathrm{H} 2 \mathrm{~S}$ using room temperature ionic liquid [bmim] [PF6], Fluid Phase Equilibria, 294 (2010) 105-113.

[11] W. Quan, X. Wang, C. Song, Selective removal of $\mathrm{H}_{2} \mathrm{~S}$ from biogas using solid amine-based "molecular basket" sorbent, Energy Fuels, 31 (2017) 9517-9528.

[12] R. T. Driessen, M. J. Bos, D. W. F. Brilman, A multistage fluidized bed for the deep removal of sour gases: proof of concept and tray efficiencies, Ind. Eng. Chem. Res., 57(2018) 3866-3875.

13] J. Li, Z. Dai, M. Usman, Z. Qi, L. Deng. $\mathrm{CO}_{2} /$ $\mathrm{H}_{2}$ separation by amino-acid ionic liquids with polyethylene glycol as co-solvent. Int. J. Greenhouse Gas Control, 45(2016) 207-215. 
[14] A.S. Rewar, S.V. Shaligram, U.K. Kharul, Polybenzimidazole based polymeric ionic liquids possessing partial ionic character: effects of anion exchange on their gas permeation properties, J. Membrane Sci., 497 (2016) 282-288.

[15] M.d. Sakinul Islam, K. N. Dhanavath, N. Kao, P. K. Bhattacharjee, B. Si-Ali, R.Yusoff, Carbon dioxide induced degradation of diethanolamine during absorption and desorption processes, Chinese J. Chem. Eng., 26 (2018) 293-302.

[16] S. Yar-Khan, M. Yusuf, A. Malani, Selection of amine in natural gas sweetening process for acid gases removal: A review of recent studies, petrol. petrochem. Eng. J., 1 (2017)1-7.

[17] F. L. Bernard, F. Dalla Vecchia, M. F. Rojas, R. Ligabue, M. O. Vieira, E. M. Costa, Vitaly V. Chaban, S. Einloft, Anticorrosion Protection by Amine-Ionic Liquid Mixtures: Experiments and Simulations, J. Chem. Eng. Data, 61 (2016) 18031810.

[18] H. Lü, C. Deng, W. Ren, X. Yang, Oxidative desulfurization of model diesel using $\left[\left(\mathrm{C}_{4} \mathrm{H}_{9}\right)_{4} \mathrm{~N}\right]_{6} \mathrm{Mo}_{7} \mathrm{O}_{24}$ as a catalyst in ionic liquids, Fuel Process. Technol., 119 (2014) 87-91.

[19] Y. Nie, C.X. Li, H. Meng, Z.H. Wang, N,Ndialkylimidazolium dialkylphosphate ionic liquids: their extractive performance for thiophene series compounds from fuel oils versus the length of alkyl group, Fuel Process. Technol., 89 (2008) 978-983.

[20] A.A. Miran Beigi, M. Abdouss, M. Yousefi, S.M. Pourmortazavi, A.Vahid, Investigation on physical and electrochemical properties of three imidazolium based ionic liquids (1-hexyl-3-methylimidazolium tetrafluoroborate, 1-ethyl-3-methylimidazolium bis(trifluoromethylsulfonyl) imide and 1-butyl-3methylimidazolium methylsulfate), J. Mol. Liq., 177 (2013) 361-368.

[21] L. Wang, Y. Xu, Z. Li, Y. Wei, J. Wei, $\mathrm{CO}_{2} / \mathrm{CH}_{4}$ and $\mathrm{H}_{2} \mathrm{~S} / \mathrm{CO}_{2}$ selectivity by ionic liquids in natural gas sweetening, Energy Fuels, 32 (2018) 10-23.

[22] F. Billeci, F. D. Anna, H. Q. Nimal Gunaratne, N. V. Plechkova, K. R. Seddon, Ionic liquid gels: materials for sweetening of fuels, Green Chem., 20 (2018) 4260-4276.

[23] Y. Zhao, H. Gao, X. Zhang, Y. Huang, D. Bao, S. Zhang, Hydrogen Sulfide Solubility in Ionic Liquids (ILs): An Extensive Database and a new ELM model mainly established by imidazoliumbased ILs, J. Chem. Eng., 61 (2016) 3970-3978.

[24] J.X. Zhou, J.B. Mao, S.G. Zhang, Calculations of the interaction between thiophene and ionic liquids, Fuel Process. Technol., 89 (2008) 1456-1460

[25] Cecilia Devi Wilfred, Chong Fai Kiat, Zakaria Man, M. Azmi Bustam, M. Ibrahim M. Mutalibb, Chan Zhe Phak, Extraction of dibenzothiophene from dodecane using ionic liquids, Fuel Process. Technol., 93 (2012) 85-89

[[27] W. Zhu, W. Huang, H. Li, M. Zhang, W. Jiang, G. Chen, C. Han, Polyoxometalate-based ionic liquids as catalysts for deep desulfurization of fuels, Fuel Process. Technol., 92 (2011) 1842-1848.

[28] D. Zhao, Y. Wang, E. Duan, J. Zhang, Oxidation desulfurization of fuel using pyridinium-based ionic liquids as phase-transfer catalysts, Fuel Process. Technol., 91 (2010) 1803-1806

[29] H. Shirkhanloo, Sara Davari Ahranjani, A lead analysis based on amine functionalized bimodal mesoporoussilica nanoparticles in human biological samples by ultrasoundassisted-ionic liquid trapmicro solid phase extraction, J. Pharm. Biomed. Anal., 157 (2018) 1-9

[30] A. Faghihi-Zarandi, H. Shirkhanloo, C. Jamshidzadeh, A new method for removal of hazardous toluene vapor from air based on ionic liquid-phase adsorbent, Int. J. Environ. Sci. Tech., Accepted: 16 August 2018, Doi.org/10.1007/ s13762-018-1975-5.

[31] H. Sid Kalal, A.A. Miran Beigi, M. Farazmand, Sh.A. Tash, Determination of trace elemental sulfur and hydrogen sulfide in petroleum and its distillates by preliminary extraction with voltammetric detection, Analyst, 125 (2000) 903-908. 